\title{
Ensino de termologia: uma proposta de sequência didática baseada na pedagogia
}

\section{histórico-crítica}

\author{
Teaching of thermology: a proposal of didactic sequence based on the historical-critical pedagogy \\ La enseñanza de la termología: una propuesta de secuencia didáctica basada en la pedagogía \\ crítico-histórica
}

Recebido: 20/09/2021 | Revisado: 24/09/2021 | Aceito: 25/09/2021 | Publicado: 27/09/2021

\author{
Manuel Messias Santos Batista \\ ORCID: https://orcid.org/0000-0002-0459-6812 \\ Universidade Federal de Sergipe, Brasil \\ E-mail: manumsantos2008@hotmail.com \\ Divanizia do Nascimento Souza \\ ORCID: https://orcid.org/0000-0001-9634-7380 \\ Universidade Federal de Sergipe, Brasil \\ E-mail: divanizia@gmail.br
}

\begin{abstract}
Resumo
Neste artigo apresentamos uma sequência didática que foi elaborada para o ensino de conceitos de Termologia com base nos pressupostos teóricos da pedagogia histórico-crítica (PHC). Essa pedagogia considera o homem como ser histórico, construído ao longo do tempo, sendo a educação um processo fundamental para essa humanização. A sequência didática, que tem como tema "O aquecimento global", foi estruturada com base nos cinco passos estruturadores da PHC e vivenciada com alunos da segunda série do Ensino Médio, durante aulas da disciplina Física. Ao longo das atividades os alunos foram observados e responderam a um questionário. Com as observações e análises das respostas, foi desenvolvido um estudo empírico de abordagem qualitativa. As análises dos dados após as atividades da sequência didática confirmaram um maior conhecimento de parte dos alunos sobre os conceitos de Termologia discutidos em comparação ao momento inicial da sequência. Reações diversas desses alunos, como demonstrações de autonomia, espontaneidade e expectativa para participar das ações da sequência, confirmaram que os cinco passos propostos na PHC contribuíram para a compreensão do contexto social.
\end{abstract}

Palavras-chave: Ensino de termologia; Pedagogia Histórico-Crítica; Sequência didática.

\begin{abstract}
In this article we present a didactic sequence that was developed for teaching of concepts of Thermology based on theoretical assumptions of historical-critical pedagogy (HCP). This pedagogy understands man as a historical being, built over time, and education as a fundamental process for this humanization. The didactic sequence, which has the theme "Global warming", was structured based on the five structuring steps of HCP and experienced with students of the second grade of High School, during physics classes. Throughout the activities the students were observed and answered a questionnaire. With the observations and analysis of the responses, an empirical study with a qualitative approach was developed. The analysis of the data after the activities of the didactic sequence confirmed a greater knowledge on the part of the students about the concepts of Thermology discussed in comparison to the initial moment of the sequence. These students' diverse reactions, such as demonstrations of autonomy, spontaneity, and expectation to participate in the sequence's actions, confirmed that the five steps proposed in HCP contributed to their understanding of the social context.
\end{abstract}

Keywords: Teaching thermology; Critical-Historical Pedagogy; Didactic sequence.

\section{Resumen}

En este artículo presentamos una secuencia didáctica desarrollada para la enseñanza de conceptos de termología basada en los supuestos teóricos de la pedagogía histórica crítica (PHC). Esta pedagogía considera al hombre como un ser histórico, construido a lo largo del tiempo, y la educación es un proceso fundamental para esta humanización. La secuencia didáctica, cuyo tema es el "Calentamiento Global", se estructuró con base en los cinco pasos estructurantes del APS y se experimentó con los alumnos de la segunda serie de escuela secundaria, durante las clases de Física. A lo largo de las actividades, los alumnos fueron observados y respondieron a un cuestionario. Con las observaciones y el análisis de las respuestas, se desarrolló un estudio empírico de enfoque cualitativo. El análisis de los datos tras las actividades de la secuencia didáctica confirmó un mayor conocimiento de una parte de los alumnos sobre los conceptos de termología tratados en comparación con el momento inicial de la secuencia. Las diferentes reacciones de estos alumnos, como las demostraciones de autonomía, la espontaneidad y la expectativa de participar en las acciones 
de la secuencia, confirmaron que los cinco pasos propuestos en el PHC contribuyeron a la comprensión del contexto social.

Palabras clave: Enseñanza de la termología; Pedagogía Histórica-Crítico; Secuencia didáctica.

\section{Introdução}

Neste trabalho, que resulta de um projeto de mestrado (Santos, 2019), são apresentadas reflexões sobre a aplicação dos cinco passos estruturadores da pedagogia histórico-crítica (PHC), definidos por Saviani (2003), em uma sequência didática para o ensino de conceitos de Termologia no Ensino Médio. Os passos estruturadores da PHC são: partir do social; problematização; instrumentalização; catarse; e retorno à prática social (Saviani, 2003; Sátiro, 2005). O objetivo desta pedagogia é aplicar tais passos como ferramenta para promover uma educação capaz de libertar o indivíduo de um estado de alienação social, possibilitando-o compreender o contexto social em que ele está inserido.

A pedagogia histórica-crítica, proposta por Dermeval Saviani ao final da década de 1970, anseia pela transformação social e assume ser capaz de tirar o indivíduo de um estado de alienação, possibilitando que ele tenha uma visão ampla do contexto em que ele vive. A PHC considera a intencionalidade por traz da produção do conhecimento científico, que se dá em espaço e tempo determinados (Saviani, 2011). Isso porque, muitas vezes, o conhecimento é produzido para atender a necessidades urgentes de uma determinada época, obedecendo principalmente a fins capitalistas. Então, a centralidade da PHC não é o professor ou o aluno, esses são agentes da prática social e o conhecimento o seu eixo (Batista \& Lima, 2015).

A PHC é um meio articulado de ensinar ciências, por valorizar o conhecimento clássico, constituído das invenções e descobertas científicas ao longo do tempo (Sátiro, 2005). Neste sentido, "clássico é aquilo que se firmou como fundamental, como essencial" (Saviani, 2003, p. 13). Essa valorização é expressa no terceiro passo estruturador, que corresponde à instrumentalização, sendo essa a etapa em que os conteúdos curriculares clássicos são efetivamente mediados pelo professor. Essa também é a etapa em que o aluno se apropria das ferramentas culturais necessárias à luta social.

É importante que o trabalho do professor não consista somente em mediar os conteúdos curriculares clássicos, visto que tão-somente a aprendizagem desses conteúdos não dá conta de promover a formação de um cidadão crítico; por isso há a necessidade do primeiro e quinto passos definidos por Saviani. Para que o aluno estabeleça conexões entre o que ele aprende e o contexto histórico-social em que vive, é necessário que os conteúdos clássicos sejam contextualizados. É preciso partir do social e retornar a ele enquanto um conteúdo é ensinado ao aluno. Esse movimento auxilia a esclarecer ao aluno que o conteúdo estudado tem uma função social, e que foi produzido em um contexto específico, tendo assim uma intencionalidade. Mas, para isso, o professor deve ter uma formação docente sólida, que o leve a compreender os conhecimentos científicos básicos, propostos sob a forma de conteúdos curriculares em suas disciplinas. Essa formação permitirá ao professor contribuir para a evolução do conhecimento empírico dos alunos, instrumentalizando-os efetivamente, para que alcancem o conhecimento científico (Mashiba \& Gasparin, 2018). E isso será mais efetivo quando o professor for capaz de compreender relações entre a sua prática e a prática social global (contexto socioeconômico e realidade social) (Saviani, 2011; Teixeira, 2003).

Saviani compreende que a prática social global abrange a educação como um todo e a educação escolar, considerando que a educação é uma mediação entre a totalidade social e a singularidade do aluno, pela ação do professor e do aluno. Então, a prática social global está presente no início do processo educativo, bem como em seu final (Saviani, 2011). Os três momentos essenciais da PHC são problematização, instrumentalização e catarse, sempre envoltos pela prática social global. Assim, a educação escolar está sempre contida na prática social global.

A tarefa a que se propõe a PHC em relação à educação escolar implica em três ações (Sátiro, 2005): 
a) Identificação das formas mais desenvolvidas em que se expressa o saber objetivo produzido historicamente, reconhecendo as condições de sua produção e compreendendo as suas principais manifestações bem como as tendências atuais de transformação;

b) Conversão do saber objetivo em saber escolar de modo a torná-lo assimilável pelos alunos no espaço e tempo escolares;

c) Provimento dos meios necessários para que os alunos não apenas assimilem o saber objetivo enquanto resultado, mas apreendam o processo de sua produção bem como as tendências de sua transformação.

Considerando essas três ações, a etapa partir do social (prática social) serve para identificar os conhecimentos prévios dos alunos sobre o tema abordado nas aulas. A etapa retorno à prática social (prática social final) possibilita entender o novo nível de consciência adquirido pelos alunos e a possibilidade de eles colocarem em execução o que aprenderam. Mas, na PHC, é importante que o professor tenha claro que mesmo que o tema ou a unidade de conteúdo abordados se caracterizem como prática social comum a professor e aluno (Sátiro, 2005), esses indivíduos, que são agentes da prática social, podem se posicionar diferentemente quanto à essa prática. Contudo, essa diferença de compreensão não se faz presente no momento catarse, sendo esse o momento em que o aluno se iguala ao nível do professor quanto à prática social.

Conforme definição apresentada em dicionário da língua portuguesa (Ferreira, 2010), na catarse a liberação de pensamento e emoções que estavam reprimidos no inconsciente, seguindo-se de alívio emocional. Na catarse, tem-se o momento da nova forma de entendimento da prática social, em que o conteúdo mediado se torna efetivamente elemento de mudança social (Sátiro, 2005; Saviani, 2011).

\subsection{A abordagem da PHC no contexto educacional}

Dentre os variados exemplos de abordagem da PHC no contexto educacional, a descrita por Lima e Cunha (2016) trata do ensino dos conceitos ácido e base na perspectiva histórico-crítica. Os autores, em aulas da disciplina Química para alunos da primeira série do Ensino Médio, quando empregaram pedagogias próximas da tradicional e da pedagogia nova, observaram que as concepções deles permaneciam ricas em ideias do senso comum. Esse resultado foi atribuído em parte ao tipo de pedagogia aplicada. Por isso, em uma sequência didática de seis aulas, esses autores buscaram vivenciar com os alunos os cinco momentos da PHC visando ampliar tais concepções. Para iniciar a sequência de aulas, os alunos tiveram oportunidade de ler notícias, previamente escolhidas, abordando conteúdos sobre saúde, cosméticos e agricultura, que são temas sociais. As notícias envolviam conhecimentos relacionados a ácidos e bases. Na segunda aula, os alunos responderam a questões relacionadas às notícias, que problematizavam o tema que seria estudado, conduzindo-os a perceber que a solução dos problemas relatados nas notícias demandaria a apropriação de conceitos do conteúdo químico que seria estudado. Na terceira e na quarta aula, para que os alunos pudessem perceber os processos de construção dos conhecimentos científicos envolvidos, o conteúdo foi abordado historicamente, como forma de instrumentalizar os alunos a partir da apresentação dos conceitos ácido e base. Na quinta aula, o momento da catarse foi motivado com a apresentação de seminários pelos alunos, que discutiram notícias e soluções para os problemas relatados nelas. Na última aula, o retorno à prática social se deu a partir da elaboração de vídeos pelos alunos, inspirados nas notícias e soluções propostas.

Frederico e Campos (2016) problematizaram a contribuição do materialismo histórico-dialético para a questão ambiental, destacando que algumas afirmações da PHC são de grande importância para a materialização de políticas públicas e práticas em educação ambiental. No estudo, autores retomaram alguns dos pressupostos de uma epistemologia crítica e da ontologia do ser social nos termos do materialismo histórico-dialético. Em seguida, consideraram categorias que contribuem para a reflexão sobre os rumos da educação ambiental. Eles caracterizam como movimento ontológico o modo de produção 
humana. Nesse movimento, o ser natural se constitui também como ser social, revelando a educação como uma exigência do tornar-se humano, o que resulta na afirmação de que não há sociedade sem educação.

Mais recentemente, Diniz e Campos (discutiram sobre a importância da PHC como referencial teórico a ser abordado na formação de professores de Ciências e Biologia, de forma a contribuir para que esses profissionais se comprometam "com a educação escolar humanizadora e com a transformação social". Na discussão, os autores chamam a atenção para o fato que a formação de professores é um processo em que o senso comum está muito presente; para superar isso, defendem quatro princípios que consideram centrais à formação de professores de Ciências e Biologia, estando os princípios pautados na reflexão filosófica, em concordância com a PHC. Esses princípios são: "crítica e transformação da sociedade capitalista e articulação dialética entre educação escolar e sociedade; visão histórica de ser humano; papel transformador do conhecimento sistematizado e da escola e metodologia dialética de ensino" (Diniz \& Campos, 2020).

A possibilidade de contribuição da PHC para a educação não formal em museus e centros de ciências também tem sido motivo de análise. Conforme Mori e Curvelo (2016), os processos educativos que se dão nessas instituições podem ocorrer em consonância com a teoria de Saviani. No artigo, os autores identificam possibilidades de articulação entre as ações de educação científica não formal com o ensino escolar, devendo a primeira se subordinar à segunda para que um processo crítico e transformador possa se instaurar durante as ações.

Entendendo que a PHC é atual, é de se esperar que tal pedagogia esteja ainda em processo de consolidação e, talvez por isso, foi encontrado somente o trabalho de Rubino (2010), antes do nosso (Santos, 2019), abordando atividades relacionadas à disciplina Física. Assim, é importante que essa pedagogia seja experimentada mais vezes no ensino dos conteúdos dessa disciplina na escola básica, de forma que se tenha um entendimento mais amplo acerca da sua potencialidade para a promoção da compreensão de conteúdos curriculares clássicos vinculados ao contexto social em que os alunos estão inseridos.

É importante esclarecer que consideramos neste estudo que a pedagogia histórico-crítica se alinha ao Movimento Ciência, Tecnologia e Sociedade no ensino de ciências, pois, conforme Teixeira (2003, p. 188), ambos podem "subsidiar os processos de formação e a proposição de novas experiências de ensino-aprendizagem na área de ciências".

\subsection{Termologia no dia a dia}

No cotidiano, mais especificamente no ambiente doméstico, são observadas diversas situações envolvendo os conceitos de calor e temperatura. No livro "Física do dia a dia 2", organizado por Carvalho (2011), são exemplificadas questões referentes às situações que fazem parte do nosso cotidiano, como as seguintes:

1. Por que, normalmente, o congelador fica sempre na parte de cima das geladeiras?

2. Por que os cabos de panelas são de madeira ou de plástico?

3. O bebê está chorando e o leite fervido ainda está quente. O que esfriará o leite mais rapidamente: colocar a mamadeira na geladeira ou colocá-la em uma panela com água da torneira?

Para responder a tais questões são necessários conhecimentos básicos de Termologia. Embora a Base Nacional Comum Curricular (Brasil, 2018) não sugira em que série do Ensino Médio os conteúdos relacionados à Termologia devam ser mediados com maior ênfase, isso normalmente ocorre na $2^{a}$ série. Uma vez que esses conhecimentos sejam adquiridos, esperase que eles possibilitem, inclusive: "Realizar previsões, avaliar intervenções e/ou construir protótipos de sistemas térmicos que visem à sustentabilidade, com base na análise dos efeitos das variáveis termodinâmicas e da composição dos sistemas naturais e tecnológicos" (Brasil, 2018). 
Conceitualmente, o calor enquanto transferência de energia térmica foi pouco compreendido até meados do século XIX (Pietrocola, 2005). Somente no início do século XVIII, com a evolução dos termômetros, o calor passou a ser estudado com mais ênfase do ponto de vista científico, com menor aporte em suposições filosóficas.

Para uma melhor compreensão sobre a temperatura de um corpo se faz necessário um entendimento microscópico da matéria. O modelo cinético-molecular da matéria inclui os pressupostos fundamentais em que a teoria cinético-molecular se baseia. Esses pressupostos são: todas as substâncias são constituídas de moléculas que representam a menor parte da matéria capaz de conservar as mesmas propriedades químicas; tais moléculas estão em contínuo movimento caótico ou desordenado; a curta distância, as moléculas interagem entre si. Esses pressupostos contribuem para a interpretação da matéria nos três estados físicos, gasoso, líquido e sólido. Sendo a temperatura uma grandeza física associada à energia cinética das moléculas, com o aumento da velocidade de agitação das moléculas há um aumento da temperatura do meio que as contém; da mesma forma, com a diminuição da velocidade das moléculas há uma diminuição na temperatura desse meio.

A consideração da importância do conhecimento dos conceitos básicos de Termologia para que o jovem tenha uma visão ampla do contexto em que ele vive motivou a proposição da sequência didática apresentada a seguir, pautada nos cinco passos estruturadores da PHC.

\section{Metodologia}

A proposta de ensino aqui apresentada consistiu em uma sequência didática com momentos que coincidem com os cinco passos estruturadores da PHC. O estudo foi desenvolvido como uma pesquisa empírica de abordagem qualitativa, tendo em vista que os seus resultados caracterizam os resultados de uma experiência (Santos, 2019).

A sequência didática foi vivenciada por duas turmas do $2^{\circ}$ ano do Ensino Médio de uma escola pública estadual de Sergipe. As atividades ocorreram durantes as aulas regulares, no turno da tarde. Participaram da sequência didática 54 alunos, com idades entre 16 e 17 anos, sendo 33 deles de uma turma e 21 de outra. As informações ao longo das observações foram coletadas com o consentimento prévio dos alunos e de seus responsáveis legais.

Como instrumento de coleta de dados foram adotados o questionário e as gravações de áudio. O questionário aplicado, apresentado no item anterior, é composto de questões objetivas, com foco na diferença entre calor e temperatura, e três questões discursivas planejadas com a intenção de obter dos alunos um posicionamento com procedimentos envolvendo a abordagem Ciência-Tecnologia-Sociedade-Ambiente (CTSA). Previamente, o questionário foi validado por alunos e ex-alunos da graduação em Física da Universidade Federal de Sergipe.

Para a análise dos dados foram considerados elementos de Análise Textual Discursiva, descritos por Moraes e Galiazzi (2011), que apresentam elementos principais que constituem um ciclo em torno de alguns dos focos do discurso. Na análise, foram empregados os seguintes elementos descritos por esses autores: desmontagem dos textos, que implica em desconstrução e unitarização, e estabelecimento de relações, que se refere ao processo de categorização.

\subsection{Sequência didática proposta}

A sequência didática desenvolvida envolve conceitos de Termologia, tendo como tema "O aquecimento global". Esse é um tema atual, sendo abordado frequentemente nos noticiários jornalísticos. Como discussões sobre aquecimento global podem ser facilmente motivadas em aulas da disciplina Física envolvendo conteúdos de Termologia, optamos por vivenciar a sequência em aulas da disciplina Física em turmas de segunda série do Ensino Médio. O tema escolhido abrange conceituação sobre diferença entre calor e temperatura, processos de transmissão de calor e medição da temperatura. A sequência foi dividida em três etapas: Etapa 1 - Partir do Social e Problematização; Etapa 2 - Instrumentalização e; Etapa 3 - Retorno à 
Prática Social e Catarse. Inicialmente, a proposta do que seria abordado na sequência didática foi apresentada aos alunos. Em seguida, os alunos responderam ao questionário que está apresentado mais adiante.

Para partir do social, consideramos que o tema "Aquecimento global" é polêmico, inclusive pelo fato de existirem pessoas que não acreditam que esse aquecimento é uma realidade. O tema, que é constantemente objeto de noticiários jornalísticos, foi problematizado a partir de um recorte de um texto intitulado "A análise do efeito estufa em textos paradidáticos e periódicos jornalísticos", de Xavier e Kerr (2004), e por meio do vídeo "O que é aquecimento global?", disponível no Portal eCycle (2017).

$\mathrm{Na}$ segunda etapa ocorreu o passo de instrumentalização dos alunos. Os conceitos escolhidos para a instrumentalização sobre Termologia são os descritos em dois capítulos do livro texto de autoria de Martini e colaboradores (2016), adotado na escola onde a sequência foi vivenciada. Em um dos dois capítulos são apresentadas as diferenças entre calor e temperatura e os processos de transmissão do calor. No outro capítulo são abordados conceitos como escalas termométricas e conversão de unidades de temperatura entre as escalas. Consideramos que esses são conhecimentos necessários para a compreensão do tema proposto inicialmente, como ponto de partida do social. O professor, que é o primeiro autor deste artigo, explicou a diferença entre calor e temperatura, como medir a temperatura utilizando diferentes escalas termométricas e os vários processos de transmissão do calor. A instrumentalização foi continuada com um experimento para demonstração do efeito estufa. Para isso, foram construídas pequenas estufas, empregando, basicamente, caixas de papelão com uma janela transparente na tampa.

Os alunos tiveram a oportunidade de expor as estufas ao sol e medir a temperatura da água, contida em copos plásticos, dentro e fora das estufas. Era esperado que eles observassem que a temperatura dentro das estufas expostas ao sol era mais elevada que fora delas, sendo esse aquecimento decorrente do plástico utilizado na janela da estufa impedir a reflexão total dos raios de luz proveniente do Sol para o ambiente ao redor dela, mantendo o interior da estufa mais aquecido.

Os materiais necessários para as aulas expositivas foram quadro, pincel para quadro branco e projetor multimídia. O experimento da estufa, que foi construído com a ajuda dos alunos, demandou copos, papel alumínio, plástico filme, caixa de papelão (do tipo empregada para embalar sapado, por exemplo), além de termômetro de mercúrio e digital. Para a montagem do termômetro digital seguimos as instruções apresentadas por Moreira e Celeste (2012), empregando um multímetro digital, uma placa protoboard, uma pilha de $9 \mathrm{~V}$, um sensor de temperatura, um resistor de $2 \mathrm{k} \Omega$ e cabos de conexão.

Nas Figuras 1a e 1b estão apresentadas fotografias do termômetro digital montado com os alunos e das estufas expostas ao sol. Após a exposição das estufas ao sol, os alunos mediram a temperatura da água contida no copo que estava dentro da estufa e da que estava no copo fora da estufa. Com os dados obtidos, eles construíram uma tabela para informar as temperaturas registradas.

Para a promoção do retorno à prática social, um seminário sobre o tema "Acordo Climático de Paris foi realizado com os alunos. Conforme consta no portal eletrônico do Ministério do Meio Ambiente, o objetivo central desse acordo, estabelecido entre 195 países em 2016, foi “fortalecer a resposta global à ameaça da mudança do clima e de reforçar a capacidade dos países para lidar com os impactos decorrentes dessas mudanças" Portal eCycle (2017). O tema foi dividido nos tópicos listados a seguir e os alunos, em grupos, pesquisaram sobre um dos tópicos para as apresentações.

- Acordo de Paris: o que é e objetivos.

- Principais pontos do acordo de Paris sobre o clima.

- A indústria brasileira e o acordo de Paris.

- A saída dos Estados Unidos do acordo climático de Paris. 
Figura 1 - a) Termômetro digital montado com os alunos. b) Estufas e copos expostos ao sol

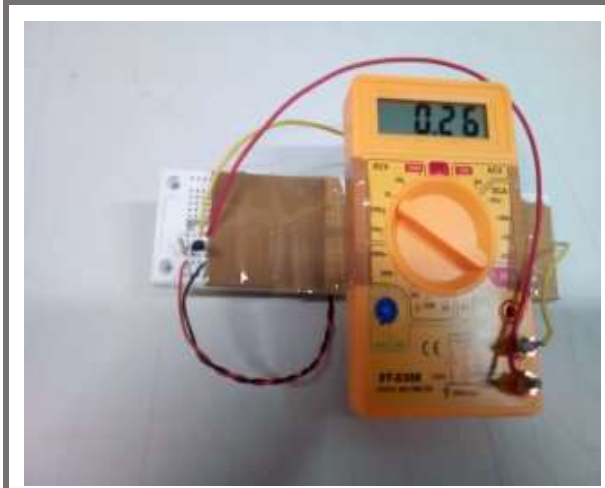

(a)

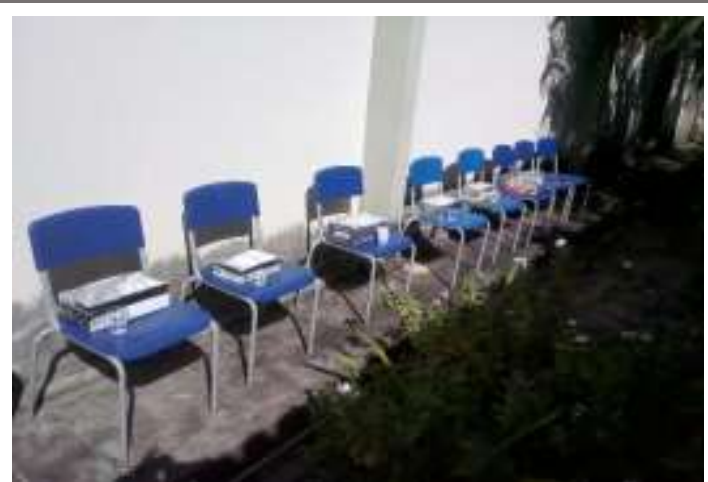

(b)

Fonte: Santos (2019)

Após as apresentações, os alunos que respondessem novamente ao questionário inicial. Isso serviu para avaliar se houve ou não mudanças nas suas respostas em função da sequência didática. Essa segunda aplicação do questionário correspondeu ao momento da catarse, em que se espera que os alunos tenham uma compreensão aprimorada do tema e conceitos estudados em comparação ao que eles informaram no questionário inicial.

As atividades da sequência didática foram realizadas em 9 aulas de 50 minutos. As etapas, considerando os cinco passos estruturadores da PHC, estão descritas no Quadro 1.

Quadro 1 - Sequência didática proposta para abordagem de conteúdos de Termologia, considerando os cinco passos estruturadores da pedagogia histórico-crítica.

\begin{tabular}{|c|c|c|}
\hline Etapas & Aula & Ação \\
\hline \multirow[b]{3}{*}{$\begin{array}{l}\text { Partir do Social e } \\
\text { Problematização }\end{array}$} & 1 & $\begin{array}{l}\text { Apresentação da proposta a ser desenvolvida na sequência. } \\
\text { Aplicação do questionário prévio. }\end{array}$ \\
\hline & 2 & $\begin{array}{l}\text { Partir do social com tema "O aquecimento global" e começar a problematização a partir } \\
\text { da leitura de um recorte do texto "A análise do efeito estufa em textos paradidáticos e } \\
\text { periódicos jornalísticos". }\end{array}$ \\
\hline & 3 & $\begin{array}{l}\text { Continuação da problematização sobre o tema proposto, com a exibição do vídeo "O que } \\
\text { é aquecimento global?" (Portal eCycle). } \\
\text { Após a exibição do vídeo, o professor apresenta à turma as questões norteadoras para } \\
\text { motivar a discussão: } \\
\text { 1. O que é o efeito estufa? } \\
\text { 2. O que é o aquecimento global? } \\
\text { 3. O ser humano tem contribuído com o aquecimento global? Detalhe a sua opinião. }\end{array}$ \\
\hline \multirow{4}{*}{ Instrumentalização } & 4 & $\begin{array}{l}\text { O professor apresenta explicações sobre diferença entre calor e temperatura e descreve os } \\
\text { processos de transmissão do calor. }\end{array}$ \\
\hline & 5 & $\begin{array}{l}\text { O professor aborda sobre medição da temperatura de um corpo utilizando as escalas } \\
\text { Celsius, Fahrenheit e Kelvin e sobre conversão de temperatura entre essas escalas. }\end{array}$ \\
\hline & 6 & $\begin{array}{l}\text { O professor orienta os alunos na construção de estufas e medição de temperatura } \\
\text { utilizando o termômetro de mercúrio e o termômetro digital. } \\
\text { São realizadas comparações entre as medições. }\end{array}$ \\
\hline & 7 & Resolução de exercícios para fixação do conteúdo. \\
\hline \multirow{2}{*}{$\begin{array}{l}\text { Retorno à Prática } \\
\text { Social e Catarse }\end{array}$} & 8 & Os alunos apresentam um seminário sobre o acordo climático de Paris. \\
\hline & 9 & Os alunos respondem ao mesmo questionário inicial. \\
\hline
\end{tabular}




\subsection{Questionário}

O questionário aplicado na primeira aula constou das seis primeiras questões apresentadas a seguir. Ao final da sequência didática, o questionário foi reaplicado com o acréscimo da sétima e da oitava questão. Essas duas últimas questões, que foram respondidas no início de uma aula ocorrida depois da $9^{a}$, são de provas do Exame Nacional do Ensino Médio (ENEM), edição 2010 e 2016, respectivamente.

\section{Há diferença entre calor e temperatura? ( ) Sim （ ) Não}

2. A partir da explicação apresentada na figura a seguir, responda: o que há de errado na afirmação "Eu estou com calor"?

Figura 1. Imagem de explicação da pergunta.

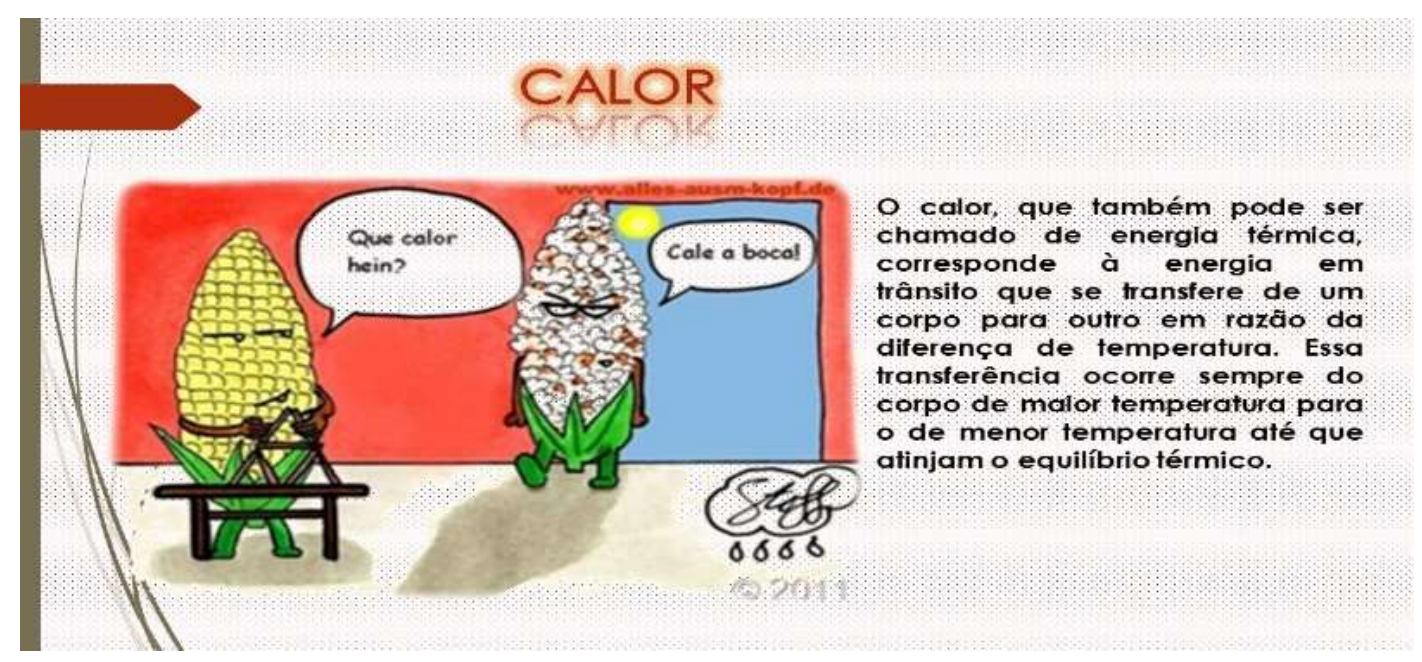

Fonte: http://player.slideplayer.com.br/2/5604221/data/images/img7.png - acesso em 30/08/2021.

\section{As escalas termométricas medem: ( ) Calor ( ) Temperatura ( ) Calor e Temperatura}

4. O que deveria ser feito para reduzir a quantidade de gases poluentes na atmosfera terrestre?

5. Do ponto de vista legal, o que pode ser feito com as empresas que lançam grandes quantidades de gases poluentes na atmosfera?

6. Como você pode contribuir para a redução de gases poluentes na atmosfera?

7. Em nosso cotidiano, utilizamos as palavras "calor" e "temperatura" de forma diferente de como elas são usadas no meio científico. Na linguagem corrente, calor é identificado como "algo quente" e temperatura mede a "quantidade de calor de um corpo". Esses significados, no entanto, não conseguem explicar diversas situações que podem ser verificadas na prática.

Do ponto de vista científico, que situação prática mostra a limitação dos conceitos corriqueiros de calor e temperatura?

a) A temperatura da água pode ficar constante durante o tempo em que estiver fervendo.

b) Uma mãe coloca a mão na água da banheira do bebê para verificar a temperatura da água.

c) A chama de um fogão pode ser usada para aumentar a temperatura da água em uma panela.

d) A água quente que está em uma caneca é passada para outra caneca a fim de diminuir sua temperatura.

e) Um forno pode fornecer calor para uma vasilha de água que está em seu interior com menor temperatura do que a dele. 
8. Nos dias de frio, é comum ouvir expressões como: "Esta roupa é quentinha" ou então "Feche a janela para o frio não entrar". As expressões do senso comum utilizadas estão em desacordo com o conceito de calor da termodinâmica. A roupa não é "quentinha", muito menos o frio "entra" pela janela. A utilização das expressões "roupa e quentinha" e "para o frio não entrar" é inadequada, pois o (a)

a) roupa absorve a temperatura do corpo da pessoa, e o frio não entra pela janela, o calor é que sai por ela.

b) roupa não fornece calor por ser um isolante térmico, e o frio não entra pela janela, pois é a temperatura da sala que sai por ela.

c) roupa é uma fonte de temperatura, e o frio não pode entrar pela janela, pois o calor está contido na sala, logo o calor é que sai por ela.

d) calor não está contido num corpo, sendo uma forma de energia em trânsito de um corpo de maior temperatura para outro de menor temperatura.

e) calor está contido no corpo da pessoa, e não na roupa, sendo uma forma de temperatura em trânsito de um corpo mais quente para um corpo mais frio.

As respostas dadas pelos alunos ao serem questionados foram divididas em duas categorias, RC e RI; na categoria RC foram enquadradas as respostas consideradas certas e mais abrangentes para as questões relacionadas ao tema social abordado. $\mathrm{Na}$ categoria RI foram enquadradas as respostas consideradas incorretas e de menor abrangência. Quanto às outras questões, as respostas desses alunos foram descontruídas e enquadras cada uma delas em uma das categorias, levando em consideração o grau de abrangência das respostas. Os termos maior e menor abrangência se referem a atitudes macro e micro, respectivamente, quando considerada a diferença entre uma política pública e uma ação individual para a redução da emissão de gases poluentes. Essas atitudes macro e micro são comentadas no vídeo apresentado na $3^{\mathrm{a}}$ aula da sequência didática. As atitudes macro esperadas são aquelas que cobram do governo políticas públicas para a redução da emissão de gases poluentes que contribuem para o efeito estufa. As atitudes micro são individuais e, embora contribuam para a redução da emissão de gases poluentes, não cobram do poder público uma atitude mais abrangente. Vale informar que a resposta apresentada para a questão 3 confirmava a resposta dada na questão 1. Para a análise das respostas às outras questões, as categorias criadas para cada uma foram as seguintes:

Questão 2 - Categoria RC: calor como energia em trânsito; Categoria RI: outra relação.

Questão 4 - Categoria RC: atitudes ligadas ao poder público; Categoria RI: exemplos que caracterizam uma atitude individual.

Questão 5 - Categoria RC: aplicação de multas, por ser uma maneira de responsabilizar as empresas; Categoria RI: conscientização e outras.

Questão 6 - Categoria RC: cobrar atitudes do poder público; Categoria RI: atitudes micro (individuais e menos abrangentes).

\section{Resultados e Discussão}

Nesta seção estão apresentados os resultados e considerações relativos à análise das respostas iniciais e finais dadas pelos alunos ao questionário.

Durante a apresentação da sequência foram observadas diversas reações por parte dos alunos. Embora tenham sido evidentes algumas limitações advindas da falta do hábito deles de se apresentarem em público, pudemos inferir que os alunos preferiram o modo de aula adotado na sequência em detrimento ao das aulas ministradas pelo professor habitualmente. Essa confirmação se deve ao fato de que, ao término da última etapa da sequência, alguns alunos revelaram espontaneamente ao 
professor sua preferência pela forma como as aulas de Física tinham acontecido durante a sequência didática. Outro episódio que corroborou para essa percepção ocorreu durante a instrumentalização, quando alguns alunos, espontaneamente, tentaram ajudar seus colegas no registro da temperatura indicada no termômetro. Observamos nos alunos demonstrações de autonomia, boa expectativa e satisfação por participarem ativamente das aulas e curiosidade sobre o que ainda seria apresentado a eles nas etapas seguintes. Também durante a etapa de retorno à prática social, no seminário sobre o acordo climático de Paris, os alunos demonstraram satisfação por estarem contribuindo para a condução da construção dos seus conhecimentos. Essa maior autonomia e satisfação podem também ser entendidas como sentimento de liberdade, que é expressa pela espontaneidade dos alunos em participar ativamente das aulas, algo inédito nas aulas ministradas pelo professor nessas turmas. Esse sentimento é coerente com a perspectiva da PHC (Saviani, 2011).

Embora 54 alunos tenham participado da primeira atividade da sequência didática, alguns deles não compareceram a todas as atividades. Os dados discutidos a seguir são referentes às respostas dos 42 alunos que compareceram a todas as atividades. Desses 42 alunos, 27 eram de turma e 15 de outra turma da segunda série do Ensino Médio.

\subsection{Observações sobre as respostas dos alunos às questões 1 a 6}

Com as questões 1 e 3 tivemos o intuito de avaliar se os alunos compreendiam a diferença entre os conceitos de "calor e temperatura". A questão 1 indaga sobre essa diferença. Dos 42 alunos, 31 responderam que há diferença entre calor e temperatura. Na segunda etapa da aplicação do questionário, identificamos coerência entre as respostas de 35 dos alunos. Consideramos que somente os alunos que escolheram a alternativa "temperatura" demonstraram saber a diferença indagada na questão 1.

Para a análise da segunda questão, consideramos o critério que qualquer resposta que não apresentasse o calor como energia em trânsito estaria incorreta. Na resposta a essa segunda questão, 9 alunos relacionaram corretamente calor com a energia em trânsito na aula 1 e 13 na aula 9. Nos dois momentos, os demais alunos informaram outro tipo de relação.

As questões 4, 5 e 6 são relacionadas ao tema escolhido para partir do social. O grau de abrangência das respostas esteve diretamente relacionado com as atitudes macro ou micro que foram elencadas pelos alunos. Para a quinta questão se considerou maior grau de abrangência a menção à aplicação de multas, por exemplo, e como atitude micro qualquer menção diferente dessa.

À quarta questão, 12 alunos responderam com grau de abrangência macro na aula 1, sendo essas respostas classificadas na categoria RC. Os outros 30 alunos responderam com grau de abrangência micro e, portanto, as suas respostas foram classificadas na categoria RI. Nas respostas apresentadas na aula 9 se observou uma evolução significativa, pois 24 alunos apresentaram respostas com referência à aplicação de políticas públicas para a redução de emissão de gases poluentes na atmosfera; portanto, respostas relacionadas a atitudes macro.

A quinta questão indaga sobre o que pode ser feito do ponto de vista legal em relação às empresas que lançam grandes quantidades de gases poluentes na atmosfera. À essa questão, somente 5 dos alunos apresentaram respostas com elementos associados a atitudes macro na aula 1, com menção à aplicação de multas a tais empresas. Na aula 9,18 alunos consideraram a necessidade de aplicação de multas (atitude macro), embora outros 24 tenham apresentado respostas que não remetiam a atitudes macro. Exemplos das respostas dos alunos:

Deveria diminuir as grandes empresas que poluem muito a atmosferal Poderia reduzi-las. (Atitude macro)

Não poluir os rios, queimar lixo, queimar árvore etc. (Atitude micro)

Deveriam inventar algum meio que possa diminuir a quantidade de gases. (Atitude micro)

Pagar multa; dependendo do caso, fechamento da empresa. (Atitude macro) 
No início e ao final da sequência didática, 27 alunos responderam à sexta questão com algum grau micro de abrangência. De certa forma, isso era de se esperar, pois a pergunta remete à contribuição pessoal; embora essa contribuição possa se dar considerando o social, por meio da proposição de ações que possam ser individuais inicialmente, mas que se configurem como ponto de partida para propostas sociais. Os comentários de três alunos apresentadas na aula 9 , apresentados a seguir, ilustram isso:

Fazendo o meu papel na sociedade, cumprindo as leis e regras do país, para que preservemos a nossa cidade limpa.

Eu não fabricaria carros movidos a gasolina, porque a queima do etanol e gasolina gera fumaça.

Evitando usar combustíveis que causam poluição.

\subsection{Análise das questões de ENEM complementares ao questionário}

A sétima questão indaga sobre a diferença entre ideias do senso comum e do ponto de vista científico relativas a calor cedido a um corpo e a variação de sua temperatura. A oitava questão indaga sobre expressões do senso comum utilizadas em desacordo com o conceito científico de calor conforme a termodinâmica. Entre os 42 alunos, apenas 12 indicaram a resposta correta da sétima questão, que seria a alternativa a). Sobre a oitava questão, 9 escolheram corretamente a resposta (alternativa d). Somente 7 desses alunos responderam corretamente a essas duas questões. Assim, metade dos alunos participantes deste estudo responderam incorretamente a sétima e a oitava questão.

A Tabela 1 apresenta os resultados, em percentuais, das análises das respostas dadas pelos alunos às perguntas 1 a 5 do questionário na aula 1 (início) e na aula 9 (final). A Tabela 2 sumariza os percentuais de respostas corretas e incorretas dadas pelos alunos às questões 7 e 8 , respondidas apenas após a aula 9.

Da observação dos dados percentuais aproximados relativos às respostas dos alunos (Tabela 1), concluímos que as alterações mais significativas entre as duas etapas da aplicação do questionário foram observadas nas respostas à quarta e quinta questões. Concretamente, em relação à primeira aplicação do questionário, 12 (28,6\%) alunos haviam apresentado respostas à quarta questão que foram classificadas na categoria RC; após a sequência, $24(57,2)$ deles apresentaram opiniões classificadas como RC para essa mesma questão. Um comportamento semelhante foi observado nas respostas à quinta questão, em que foi observado um acréscimo de 30\% nas respostas classificadas como RC na segunda aplicação do questionário.

Sobre $7^{\mathrm{a}}$ e a $8^{\mathrm{a}}$ questões, menos de $20 \%$ dos alunos pareceu compreender os seus respectivos enunciados.

Nem sempre as dificuldades conceituais dos alunos estiveram relacionadas exclusivamente com o conteúdo abordado. Algumas vezes os alunos demonstraram ter adquirido novos conhecimentos sobre conceitos relacionados à Termologia, mas não foram capazes de relacioná-los corretamente. Mesmo assim, conforme Bellucco e Carvalho (2014), a contextualização dos conteúdos permite o exercício do emprego de conceitos e modelos científicos em situações do dia a dia, e isso auxilia na criação de uma relação positiva frente à Física. A utilização de estratégias diversas, que promovam modificações na forma de ensinar, permitem oportunidades para novas configurações de ensino e de aprendizagem, o que resulta em uma contextualização mais ampla dos conteúdos abordados (Santos et al., 2018). 
Tabela 1. Percentuais aproximados das respostas iniciais e finais dos alunos de acordo com as categorias.

\begin{tabular}{cccccc}
\hline & & \multicolumn{2}{c}{ Início } & & Final \\
\cline { 3 - 6 } Categorias & Questões & RC & RI & RC & RI \\
& & $(\%)$ & $(\%)$ & $(\%)$ & $(\%)$ \\
\hline Coerência entre as questões 1 e 3 & $1^{\text {a e } 3^{\text {a }}}$ & 73,8 & 26,2 & 83,3 & 16,7 \\
\hline Calor como energia em trânsito e outra relação & $2^{\text {a }}$ & 22,4 & 77,6 & 31,0 & 69,0 \\
\hline $\begin{array}{c}\text { Atitudes ligadas ao poder público e exemplos } \\
\text { que contribuem para redução de gases }\end{array}$ & $4^{\text {a }}$ & 28,6 & 71,4 & 57,2 & 42,8 \\
poluentes & & & & & \\
\hline Aplicação de multas, e conscientização das \\
empresas; e outras
\end{tabular}

Fonte: Santos (2019).

Tabela 2. Percentuais aproximados de acertos e erros das respostas dos alunos às questões 7 e 8 (questões de provas do ENEM).

\begin{tabular}{ccc}
\hline \multirow{2}{*}{ Questão } & \multicolumn{2}{c}{ Respostas } \\
\cline { 2 - 3 } & Acertos (\%) & Erros \\
& & $(\%)$ \\
\hline $\mathbf{7}^{\mathbf{a}}$ & 28,6 & 71,4 \\
\hline $\mathbf{8}^{\mathbf{a}}$ & 21,4 & 78,6 \\
\hline
\end{tabular}

Fonte: Santos (2019).

\section{Conclusão}

A estruturação da sequência didática para a abordagem de conceitos de Termologia considerando os passos estruturadores da PHC contribuiu para a mediação desses conceitos aliados ao contexto social de alunos das duas turmas do $2^{\circ}$ ano do Ensino Médio que participaram deste estudo. A cada etapa da sequência observamos reações diversas por parte dos alunos. Mas, no geral, notamos entre eles demonstrações de autonomia, o que os auxiliou a se expressarem sobre o que era solicitado, com liberdade e motivação para participar das ações da sequência. Essa participação ativa nas aulas é importante para ambos, professor e aluno. $\mathrm{O}$ aluno se sente satisfeito e motivado à medida em que o conteúdo curricular se torna relevante para ele, e o professor por presenciar a conexão realizada pelo aluno entre o contexto social e esse conteúdo escolar. Embora não tenhamos observado que os conceitos de Termologia estudados tenham sido plenamente compreendidos pelos alunos, a relação positiva deles frente à ao que foi estudado permitiu inferir que o planejamento didático de aulas de Física com base nos cinco passos estruturadores da PHC possibilita um ambiente mais propício para a aprendizagem engajada.

A vivência dos cinco passos estruturadores da PHC, como meio articulado de ensinar ciências, merece ser investigada com maior amplitude em experiências didáticas relativas a temas diversos da Física e de outras ciências. Para isso, são necessários estudos sobre a influência dessa pedagogia no desenvolvimento do pensamento crítico dos estudantes. As investigações podem ser voltadas à observação da promoção de capacidade de interpretação sobre relações entre ciência e contexto social. Almeja-se que as experiências didáticas a serem desenvolvidas, vivenciadas e observadas revelem estratégias de mobilização de professores e estudantes para debates que auxiliem na promoção da aprendizagem e da capacidade de 
argumentação científica dos envolvidos.

\section{Agradecimentos}

Ao CNPq, pelo apoio financeiro ao projeto "Interfaces entre produção acadêmica em Ensino de Ciências e saberes e práticas docentes em diferentes níveis, modalidades e espaços educativos: Aspectos relativos ao aperfeiçoamento de condições, propostas e estratégias para formação de professores", coordenado pelo Prof. Roberto Nardi (UNESP-Bauru), a partir do qual este estudo foi desenvolvido.

\section{Referências}

Santos, M. M. (2019). Ensino de termologia: uma proposta de sequência didática baseada na Pedagogia Histórico-Crítica de Dermeval Saviani (Dissertação de Mestrado). Programa de Pós-Graduação em Ensino de Ciências e Matemática. Universidade Federal de Sergipe.

Saviani, D. (2003). Escola e democracia. (36a ed.), Autores Associados, Coleção Polêmica do Nosso Tempo.

Sátiro, C. S. (2005). Ensino de ciências: abordagem histórico-crítica. Armazém do Ipê, Autores Associados.

Saviani, D. (2011). Pedagogia histórico-crítica: primeiras aproximações. (11a ed.), Autores Associados, Coleção Educação Contemporânea.

Batista, E. M. \& Lima M. R. (2015). A pedagogia histórico-crítica como teoria pedagógica revolucionária. Laplage em Revista. 2015, Set,1(3):67-81.

Mashiba, G. C. X. \& Gasparin J. L. (2018). A didática para a pedagogia histórico-crítica no estágio supervisionado do curso de pedagogia. Imagens da Educação. (3):e44239. doi.org/10.4025/imagenseduc.v8i3.44239

Teixeira P. M. M. (2003) A educação científica sob a perspectiva da pedagogia histórico-crítica e do movimento C.T.S. no ensino de ciências. Ciência \& Educação. 9(2):177-190.

Ferreira, A. B. H. (2010). Dicionário Aurélio. (5a ed.), Positivo.

Lima C. \& Cunha, M. B. M. (2016). A importância de uma abordagem histórica no ensino de ácidos e bases. In: Pinheiro B. C. S., Messeder H. S. M., Moradillo, E. F. \& Silva, J. L. P. B. (2016). Identidade e formação docente em Química. Livraria da Física, 135-150.

Diniz, R. E. S. \& Campos, L. M. L. (2020). Pedagogia histórico-crítica: princípios para formação de professores de ciências e biologia. Debates em Educação. 12(2):491-506.

Mori, R. C., \& Curvelo, A. A. S. (2016). O pensamento de Dermeval Saviani e a educação em museus de ciências. Educação e Pesquisa. 42(2) 491-506. doi.org/10.1590/S1517-9702201604144612

Rubino L. N. (2010). A física envolvida no fenômeno do efeito estufa - uma abordagem CTS para o ensino médio (Dissertação de Mestrado). Programa de Pós-Graduação em Ensino de Física, Instituto de Física. Universidade Federal do Rio de Janeiro.

Frederico C. B. L. \& Campos, M. F. T. R. (2016). Teoria social crítica e pedagogia histórico-crítica. Revista Eletrônica do Mestrado em Educação Ambiental., Ed. Especial 68-82.

Carvalho, R. P. (2011). Física do dia a dia - 105 perguntas e respostas sobre Física fora da sala de aula. (3a ed.), Autêntica Editora.

Brasil (2018). Ministério da Educação. Secretaria da Educação Básica. Base Nacional Comum Curricular, Ensino Médio. Brasília-DF, MEC, CONSED, UNDIME.

Pietrocola, M. (2005). Ensino de Física: conteúdo, metodologia e epistemologia em uma concepção integradora. (2a ed.), UFSC.

Xavier, M. A. R. \& Kerr, A. S. (2004). A análise do efeito estufa em textos paradidáticos e periódicos jornalísticos. Caderno Brasileiro de Ensino de Física. 21(3), 325-349.

Martini, G., Spilenelli W. Reis, H. C., \& Sant’Anna B. (2016). Conexões com a Física $2^{o}$ ano. (3a ed.), Moderna.

Portal eCycle (2017). O que é aquecimento global? https://www.youtube.com/watch?v=LkHvR_dL3iA.

Moreira D. C. \& Celeste, A. T. B. (2012). Construção de um termômetro para fins didáticos. Física na Escola. 13 (1), $32-34$.

Moraes, R. \& Galiazzi, M. C. (2011). Análise Textual Discursiva. Editora Unijuí.

Bellucco A. \& Carvalho, A. M. P. (2014). Uma proposta de sequência de ensino investigativa sobre quantidade de movimento, sua conservação e as leis de Newton. Caderno Brasileiro de Ensino de Física, 31(1), 30-59.

Santos G. G., Ribeiro T. N. \& Souza D. N. (2018). Aprendizagem significativa sobre polímeros a partir de experimentação e problematização. Amazônia (UFPA). 14:141-158. 